is the same as in dealing with bladder growths, and the chief diffeculties likely to be enoountered are those associated with keeping a clear field and with recognizing the exact position of the operating electrode. Obscuring of the visual field may be due to blood, debris from the destroyed tissue, and bubbles of hydrogen given off at the electrode. The first two obstacles to clear vision are removed by irrigation, and the third by rotating the instrument so that the bubbles may escape to the upper part of the field. The time required to complete the operation depends on the amount of prostate requiring removal, the strength of current, and the calibre of the electrode; it may be as much as an hour where a large amount of tissue has to be dealt with. In the simplest type of prostatic bar all that is necessary is to cut a channel through the ridge so that the level of the bladder neck is flush with that of the urethra, and to widen and deepen the channel sufficiently to provide a free exit for the urine. When some lateral enlargement is associaced with the bar formation it will be necessary to deal with this as well (sce Fig. 3). As in the case of the bar, the portion of the lateral lobes nearest the bladder should be attacked first, the optical end of the instrument being raised so that the electrode lies in the lower part of the cleft between the enlarged lateral lobes. Energetic treatment of the adenomatous masses will be necessary if the result is to be satisfactory. Both sides should be attacked at the same sitting, each portion of the obstructing lobes being brought in turn under treatment from the level of the bladder neck outwards towards the verumontanum. Where more than a slight degree of enlargement exists several sittings may be recpuired.

Very little after-treatment is necessary, and it is not my practice to tie in a catheter. A most remarkable point is the complete absence of pain or haemorrhage, or indeed of ans other complication, after this operation. What little bleeding there is at this early period is usually due to the trauma of instrumentation, and ceases within a few hours. Most patients are able to get up and, if necessary, to leave hospital or nursing home the day following the operation, and their discomfort is certainly not greater than that commonly experienced after a cystoscopy. An alteration in the stream is not usually noted for four or six days, but as sloughs begin to come away an improrement occurs. The separation of these sloughs may be encouraged by posterior irrigation according to Janet's method. In those cases in which more than one sitting is rexpuired an interval of three to four weeks should be allowed between operations so as to allow time for the separation of the sloughs and the subsidence of the reaction. The procedure at the second or third operation is exactly similar to that of the first, and as a rule it will be found that the work is considerably easier than on the previous occasions. In the majority of my own cases two sittings have been sufficient.

Summary and Conclusions.

It has already been stated that the methods of treatment described in this paper are only to be regarded as a substitute for prostatectomy in certain types of case, and that diathermy or punch operations, used indiscriminately, are bound to lead to disappointment and failure. The type of case for which these methods are eminently suitable is the prostatic bar, but fulguration may also be used against the lesser degrees of glandular enlargement when for one reason or another prostatectomy is difficult or dangerous. If, however, the prostate be considerably enlarged the results obtained will in all probability be incomplete and transitory. Fulguration may also be employed, but with less certainty of success, in cases of post-operative obstruction, and in cases of malignant disease of the hard sclerotic kind.

For the sake of convenience the conclusions reached in the foregoing paper will be tabulated as follows:

1. Total prostatectomy, in spite of a fall in mortality, must still be regarded as a serious operation and one that in many cases is attended with very considerable risks.

2. The arguments for removing all enlarged prostates as a precautionary measure against malignant disease are not entirely sound, since enucleation of a gland showing malignant changes is no guarantee against recurrence, and the immediate risk of a prostatectomy may in some cases be greater than the remote risk of malignancy.

3. Treatment by punch operations and by fulguration is of the greatest use in certain types of obstruction. These procedures are particularly suited to cases of prostatic bar, and of minor enlargement where enucleation, owing to the existence of complications, would be difficult or dangerous.

4. Success in the use of these minor operations depends on the exercise of a nice discrimination in the selection of cases. For this reason the very greatest care and thoroughness must be employed in the preliminary investigation. Otherwise the results will be uncertain and short-lived.

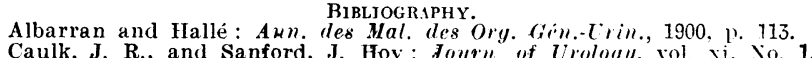
Caulk, J. R., and Sanford, J. Hoy: Journ. of Urology, rol. xi, No. 1,

Randall, Alexander:Journ. of Urolog!, 1921, p. 287. Trans. .1mer. Urol. Assuc., 1917, p. 104.

Swan, R. H. J. : Proc. Roy. Soc. Med., Section of Urology, 1923, p. 767.

Young, H. H. : Trans. Amer. Urol. Assoc., 1917, xi.

\section{THE SURGICAL TREATMENT OF CHROAIC ULCERATIVE COLITIS.}

\section{BY}

SIr THOMAS CAREY EVANS, M.C., F.R.C.S., I.M.S., SERGEON to THE hOSPITAL FOR TROPICAL DISEASES, LONDOX.

The medical treatment of chronic ulcerative colitis has, in my experience, proved extremely unsatisfactory. The ordinary intestinal antiseptics by the mouth are practically useless, and the great difficulty is to determine when activo surgical interference should be decided upon. There is no hard and fast line in determining when cases of colitis reach the rhronic stage.

There is no doubt that a large percentage of Indian troops are "carriers" of dysentery, especially of the amoebic form; in peace, when they are comfortably housed in cantonments where they have their normal rations and are not exposed to hardships and fatigues, they suffer littlo or no inconvenience. The same men under field serrice conditions, when their rations vary in quality and quantity, usually for the worse, and especially when they are exposed to cold and wet weather, soon manifest symptoms of colitis.

My own experience of these cases has been gained under field service conditions on the north-east frontier of India, 1911-13, and in Mesopotamia during the recent war. During the operations on the north-east frontier post-mortem examinations in cases of colitis revealed the intense and extensive ulceration of the large intestine which can occur the conditions impressed me with the utter hopelessness of medical treatment. It must be remembered that Indian troops are far more susceptible to scurvy than European troops; in my experience of active service, it takes about three months from the beginning of a campaign for the disease to show itself. The presence of scurvy or of a tendency to it is a very serious complication in cases of colitis and seriously aggravates the condition.

During the recent war (1914-18), while acting as surgeon to an improvised hospital for Turkish prisoners in Mesopotamia, and later as civil surgeon of Baghdad, an opportunity arose of observing a large number of cases of colitis; the majority were chronic and were complicated by scurvy. The combination of these two diseases made the colitis extremely intractable, and in consequence large numbers died.

While in Mesopotamia I performed appendicostomy for intractable ulcerative colitis in ten patients-Turks, Arabs, and Indians. They were all extreme cases, and all were complicated with scurvy in its various stages. The operations were performed under chloroform, and owing to the enaciated condition of the subjects the appendix was easily and rapidly approached in all cases. In the first two cases the appendix was not opened for two days, but in the remaining eight it was opened at the time of the operation, and lavage carried out at the same time, the round being sealed with collodion. After a few irrigations of the large intestine the patients began to show remarkable improvement. The cachectic appearance due to the intestinal autointoxication disappeared and the general condition improved 
bevond all expectations. All these cases were operated upon under very adverse conditions; there were no nurses or trained attendants to help, and there was great difficulty in obtaining fresh food and milk.

The immediate results were excellent, but it became obvious that lavage had to be persisted in for prolonged periods to maintain these results, and great care had to be taken with regard to diet. Any indiscretion in diet brought on a recurrence of the symptoms. In practically all cases eusol was used until the washings were clean, and then ordinary saline solution. The main factor was the quantity used, several pints at each lavage being essential. $I$ found that the introduction of a rectal tule for the evacuations was a great relief to the patient.

I regret that I am unable to give the after-history of these patients as they were transferred to other hospitals, and in those days, owing to the scarcity of medical staff, no accurate records could be kept. The immediate results in all cases were excellent, and this method of treatment impressed me as being the only rational procedure.

I.ater on I had an opportunity, while surgeon to the Bowring Hospital, Bangalore, of observing and treating a case in more advantageous circumstances.

Nallaridi, aged 34, was admitted to hospital on June 26th, 1920 suffering from chronic dysentery. He had had an attack of dysentery in February, 1920, from which he recovered; in April 1920, he was operated upon for haemorrhoids at another hospital.

Condition on Admission.- He was extremely emaciated and anaemic, with sunken abdominal walls. There was extreme tenderness over the left iliac region. The liver and spleen were normal in size. The motions numbered about fifty daily; they consisted of blood-stained mucus and little faecal material. Microscopica! examination showed Entamoebu histolytica and cysts to be present.

On Jume $28 \mathrm{th}$ an ipecacuanha bolus was divided into two partsche was given at 5 a.m. and the other at 2 p.m., preceded by an opium draught. Stools during the twenty-four hours numbered thirty-five. The next day emetine, grain $1 / 2$ bis in die, was given, and the stools became less frequent and less bloody.

On July 1st the patient was examined, under chloroform, with the sigmoidoscope. Several small ulcers were seen high up, and two la:ge ulcers, oval in shape with well defined edges, the bases covered with muco-pus; the intervening mucous surface was coveres with muco-pus; the intervening mucous surface was The emetine injections were continued up to July $61 \mathrm{~h}$. By this The emetine injections were continued up to July $61 \mathrm{~h}$. By this
time the stools were less frequent, but the general condition of time the stools were less f

On July 7th he was operated upon with a view of doing an appendicostomy. The appendix was found to be atrophied and useless for this purpose, so a valvular caecostomy was done, a No. 12 rubber catheter being introduced and the bowel washed out with saline solution at the conclusion of the operation.

On July 12 th the patient was doing well : the stools numbered two daily; there was no blood or mucus; temperature normal. On July 19th the general condition began to improve, the scptic appearance vanishing and diet being gradually increased with solids-ovaltine and biscuits. Injections of emetine, grain 1. Were
commenced on July 30 th and given for five days as a precaution, the bowel being still washed out twice daily.

'The bowel was washed out twice daily until Norember 13 th. and by this time the patient was practically on a fuli diet. Three dass after the irrigation ceased the fistula was almost closed, and the patient was discharged cured on December 28th, 1920, having increased over 2 st. in weight. A final sigmoidoscopic examination showed all the ulcers healed.

\section{Conclusions.}

Cilses of colitis persisting over two or three month without intermission and with profound emaciation and anaemia which do not respond to medical treatment should be handed over to the surgeon. When they reach this stage they are invariably examples of mixed infection, whatever the organism that caused the primary infection may have been. In severe cases the large intestine may be Iikened to an abscess or bag of pus.

In all chronic cases a sigmoidoscopic examination should be made. In the case recorded above sigmoidoscopic examination showed the existence of extensive ulceration of the lower bowel and confirmed the diagnosis of chronic vilcerative colitis.

The only rational treatment, when the diagnosis is confirmed, is frequent irrigation of the large intestine, either through an appendicostomy or a valvular caecostons, with ensol solution until the washings are clean; after that, with large quantities of warm saline for prolonged periods.

Valvular caecostomy is particularly mentioned, as the closing of an ordinary caecostomy may be difficuit later, hesides heing unpleasint for the patient and for those associated with him.

\section{ENTAMOEBAE AS AN ETIOLOGICAL FACTOR IN MULTIPLE ABSCESSES.}

\author{
BY \\ CLIVE J. H. SHARP, M.C., M.B., B.S.LOND., \\ D.T.M. AND H. \\ AND
}
HENRY MORRISON, M.A., M.D.C.sxta, WEST AFRICAN AIEDICAL SERVICE.

Multiple deep abscesses are of frequent occurrence in Nigeria. There are two main clinical types: (a) those which affect the muscles of the limbs, and $(b)$ those which affect the ilio-psoas muscle in particular; this type is usually single.

Although infection with Filaria bancrofti, Dracunculus inedinensis, and pyogenic organisms may explain the minority, the etiology of the majority remains a problem.'

Litamobae are frequently the causative factor in hepatio abscess; they have also been reported as occurring in abscesses of the jaw, the brain, ${ }^{2}$ the spleen, and salivary glands. $^{3}$ Still more recently Captain S. Smith ${ }^{4}$ has recorded their appearance in the left knee-joint; the patient in whom this occurred was given emetine and mado an uninterrupted recovery.

We would suggest that in view of the various organs of the body in which entamoebae have been found, there is reason to believe that amoehic pyaemia is more than a possibility.

Jonah, an African male aged 26, cook in a European household was admitted into hospital on May 26th, 1924, with a history of fever and pains which had lasted for three days. He looked extremely ill; the eyes were sunken and the tongue furred. On admission the temperature was $104^{\circ}$ and the pulse 100 . He gave no history of diarrhoea or dysentery, and stated that there had bcen no dysentery among the other boys in the household.

The temperature for the first two weeks after admission fluctuated between $100^{\circ}$ and $104^{\circ}$. On May 31st a swelling in the left arm was opened and pus eracuated. Following this there were remissions of the temperature to normal, but it still rose to $104^{\circ}$ in the evenings. On June 11th three more abscesses were opened-ono in the righi upper arm, one in the right thigh, one in the left buttock. The temperature remained high until June 30th, when it large absçess in the muscles of the back was opened. Entamoebad were present in this pus, and 8 grains of emetine were given in the doses of 1 grain-commeneing on July 2nd. On 9 th when the final dose of emetine was given. On the evening of this day it rose to $101^{\circ}$, and again to this level on July 15th. All the abscesses healed rapialy, and there is now (July 21st) only a rery. little watery discharge from the wound in the back.

Pathological Report.

On June 30thi the following facts were recorded:

Exrmination of Urine- - Nothing pathological detected.

Examination of Faeces.-The ova of Ascaris lumbricoides wero present in small numbers. No ova of Aneylostoma duodcnale were seen. No cysts or free living amoebae were noticed.

Exumination of Blood.-Blood smear : No parasites found. Blood count : Red corpuscles 2,244,000 per cubic millimetre, white corpuscles 4,375 per cubic millimetre. Differential count : Polymorphonuclear 54 per cent., eosinophil 5 per cent., lymphocyte 34 per cent., large mononuclear 7 per cent.

Excmination of Pus.-This was collected in the operating theatre under aseptic conditions during the incision of the abscess situated in the muscles of the back. The following points were noted: (a) The pus contained more red cells than one was led to expect from a macroseopic examination; (b) a large number of phagocytic leucocytes and endothelial cells of considerable size were seen; (c) the pus was sterile; but $(d)$ entamoebae were seen. The pus (r) the pus was sas from the same abscess was again examined on previous occasion. found to show the same characters as on the previous occasion.
Fresh pus was on this occasion examined in warm normal saline Fresh pus was on this occasion examined in warm normal saline noted: Entamoebac were present; they showed active amoeboid movements, but less active than those exhibited by similar entamoebae in faeces; they were definitely phagocytic and were seen to ingest red corpuscles as well as pus cells. There was a distinct differ-ntiation between the ectoplasm and the endoplasm. distinct dinter in some instances The cndoplasm was vacuolated and contained in some instances six red ceils. In the lodine preparation a distinct nucleus could be seen. Stained preparations showed the same histological characteristics. On July 3rd entamoebae were again found. On this occasion the pus was taken from another abscess located in the right 4 th.

The serious illness of the patient, the condition of the blood, the physical peculiarities and the sterility of the pus, 